\title{
Projections of future drought intensity associated with various local greenhouse gas emission scenarios in East Asia
}

\author{
Chang-Kyun Park ${ }^{1}$, Chang-Hoi Ho ${ }^{1, *}$, Rokjin J. Park ${ }^{1}$, Jung-Hun Woo ${ }^{2}$, Cheolsoo Lim ${ }^{3}$, \\ Doo-Sun R. Park ${ }^{4}$, Hoonyoung Park ${ }^{1}$, Minjoong J. Kim ${ }^{5}$, Younha Kim ${ }^{2}$, \\ Sung-Chul Hong ${ }^{3}$, and Jinwon Kim ${ }^{6}$ \\ ${ }^{1}$ School of Earth and Environmental Sciences, Seoul National University, Seoul, South Korea \\ ${ }^{2}$ Department of Advanced Technology Fusion, Konkuk University, Seoul, South Korea \\ ${ }^{3}$ National Institute of Environmental Research, Incheon, South Korea \\ ${ }^{4}$ Department of Earth Sciences, Chosun University, Gwangju, South Korea \\ ${ }_{5}^{5}$ Department of Environmental Engineering and Energy, Myongji University, Yongin, South Korea \\ ${ }^{6}$ National Institute of Meteorological Sciences, Korean Meteorological Administration, Jeju, South Korea
}

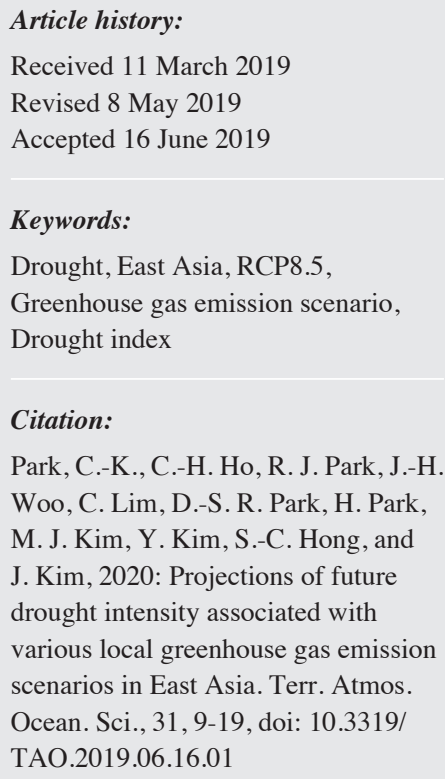

\begin{abstract}
Efforts to reduce greenhouse gas emissions are ongoing in many East Asian countries; however, their influences on future drought remain unknown. We analyzed future changes in drought intensity over East Asia using the Representative Concentration Pathway (RCP) 8.5 and the new two limiting local greenhouse gas emission scenarios in East Asia: National Institute of Environmental Research (NIER)-H scenario for high emission and NIER-L scenario for low emission. The two scenarios were made by a fully coupled global climate model with prescribed gas boundaries of high and low greenhouse gas emissions from an atmospheric chemistry model reflecting the up-to-date environmental policies of South Korea, China, and Japan. The application of a clustering analysis to the calculated drought index time series identified four zonally distributed drought regions in the present-day period (1951 - 2016). Among these regions, higher latitude regions showed a more rapidly increasing trend in drought intensity than other regions for the present-day period. All future scenarios projected the continuation of this meridional intensification trend of drought until 2100; however, the intensification rates in the NIER-L were much smaller than those in the RCP8.5 and NIER-H scenarios. Our results suggest that reducing greenhouse gas emissions is critical for East Asian countries to alleviate the potential damages of future droughts.
\end{abstract}

\section{INTRODUCTION}

Damages from severe droughts have historically been a critical concern in East Asian countries (Shen et al. 2007; Kim et al. 2011). For example, many countries in East Asia suffered huge damages due to the unforeseen extreme drought that occurred from autumn 1994 to spring 1995 (Park and Schubert 1997; Yoo et al. 2004); Rice and wheat production decreased by about $3.5 \times 10^{6} \mathrm{t}$ in Southeast Asia (Rahman and Biswas 1995), and China and South Korea lost about USD 3.2 billion in societal and agricultural sectors (NAK 2007; Zhang and Zhou 2015). It is expected that

\footnotetext{
* Corresponding author

E-mail:hoch@cpl.snu.ac.kr
}

climate change will make drought among the most serious threats to people in East Asia (Dai 2011; Park et al. 2018). Therefore, accurate projections of future droughts under realistic climate change scenarios are essential for preventing future drought damages.

A number of studies have investigated present and future droughts in East Asia using various drought indicators based solely on precipitation variations (e.g., Byun et al. 2008; Chen et al. 2013; Kim et al. 2014; Duan et al. 2015). They showed that the drought occurrence in East Asia has been increasing significantly during recent decades and this trend is likely to continue in the future (Min et al. 2003; Kim and Byun 2009; Park et al. 2015). Although precipitation deficit is crucial for droughts, the increase in environmental 
water demands also plays a decisive role (Karl et al. 2012; McEvoy et al. 2016; Wang et al. 2016). It is expected that increasing water demand due to global warming would induce more frequent water imbalance and drought in the future (Cook et al. 2014; Park et al. 2018). Thus, drought projections require quantitative assessments of the balance between water supplies and demands. The Standardized Precipitation Evapotranspiration Index (SPEI, Vicente-Serrano et al. 2010) is a suitable drought indicator for considering both the supply and demand sides of drought occurrences. The SPEI uses the water balance between precipitation and potential evapotranspiration (PET) for measuring the drought and has been shown to be reliable in diverse hydrological regions compared to the drought indices solely based on precipitation (Vicente-Serrano et al. 2012; Tan et al. 2015).

To project future drought, previous studies have usually applied the representative concentration pathway (RCP) scenarios (e.g., Cook et al. 2015; Park et al. 2015; Venkataraman et al. 2016; Schlaepfer et al. 2017; Naumann et al. 2018). RCPs are based on robust scientific agreement and have become widely accepted in various academic fields (Moss et al. 2010; Van Vuuren et al. 2011). However, the greenhouse gas emission assumptions in existing RCPs need to be updated to account for recent changes because South Korea, China, and Japan, the major emitters in East Asia, have adopted new environmental policies in recent periods (MEK 2015; CCCPC 2016; CSJ 2016). These policies include detailed plans for reducing greenhouse gas emissions via mitigation and adaptation strategies to cope with future climate change.

This study aims at investigating future changes in drought intensity over East Asia under recently introduced future climate change scenarios with consideration of the latest environmental policies of the three East Asian countries: South Korea, China, and Japan. We first estimated the greenhouse gas emission reduction plans according to the recent environmental policies of these three countries. The Goddard Earth Observing System Chemistry (GEOSChem) model was used for making the boundary dataset of greenhouse gas emissions. This dataset was then applied to a fully coupled simulation of the Community Earth System Model (CESM) to generate two updated future climate change scenarios. Finally, we projected the changes in the future drought intensity using the SPEI estimated on the basis of the two scenarios and the RCP8.5.

\section{DATA AND METHOD}

The $0.5^{\circ} \times 0.5^{\circ}$-resolution monthly gridded precipitation and PET dataset of the Climatic Research Unit (CRU; Harris et al. 2014) TS version 4.01 during 1950 - 2016 were used to calculate the drought index. The PET in CRU was estimated using the Penman-Monteith equation;

$$
P E T=\frac{0.408 \Delta\left(R_{n}-G\right)+\gamma \frac{900}{T+273.16} U_{2}(V P D)}{\Delta+\gamma\left(1+0.34 U_{2}\right)}
$$

where $R_{n}$ is net radiation at the surface $\left(\mathrm{MJ} \mathrm{m}^{-2} \mathrm{~d}^{-1}\right), G$ is the soil heat flux $\left(\mathrm{MJ} \mathrm{m}^{-2} \mathrm{~d}^{-1}\right), T$ is the average temperature at $2 \mathrm{~m}$ height $\left({ }^{\circ} \mathrm{C}\right), U_{2}$ is the wind speed measured at a height of $2 \mathrm{~m}\left(\mathrm{~m} \mathrm{~s}^{-1}\right), V P D$ is the vapor pressure deficit measured at a height of $2 \mathrm{~m}(\mathrm{kPa}), \Delta$ is the slope of the vapor pressure curve $\left(\mathrm{kPa}^{\circ} \mathrm{C}^{-1}\right)$, and $\gamma$ is the psychrometric constant $(\mathrm{kPa}$ $\left.{ }^{\circ} \mathrm{C}^{-1}\right)$. Because it uses multiple parameters such as, solar radiation, temperature, and relative humidity, for PET calculation (Allen et al. 1994), the Penman-Monteith method can guarantee reasonable spatiotemporal information of water demand variation over East Asia (Chen et al. 2005).

We calculated the SPEI, an improved drought index based on the Standardized Precipitation Index (SPI) to capture the effect of water demand (Vicente-Serrano et al. 2010), using the CRU precipitation and PET to measure the drought. Because the SPEI succeeds the concept of the flexible time scales of the SPI, it can detect droughts of various time scales from short- to long-term. In this study, we selected a 12-month time scale (normal hydrological cycle) to analyze the annual evolution of droughts in East Asia. The SPEI is calculated as below (Vicente-Serrano et al. 2010),

$S P E I=W-\frac{C_{0}+C_{1} W+C_{2} W^{2}}{1+d_{1} W+d_{2} W^{2}+d_{3} W^{3}}$

for $P \leq 0.5$ then $W=\sqrt{-2 \ln (P)}$, and $P>0.5$ then $W=\sqrt{-2 \ln (1-P)}$ and sign of SPEI is reversed. Here, $P$ is the probability of accumulated water balance (= precipitation minus PET) for certain periods (12-month in this study) according to log-logistic distribution. $C_{0}, C_{1}, C_{2}, d_{1}, d_{2}$, and $d_{3}$ are constants; $C_{0}=2.515517, C_{1}=0.802853, C_{2}=$ $0.010328, d_{1}=1.432788, d_{2}=0.189269$, and $d_{3}=0.001308$. A more negative SPEI value indicates the more dryness. Because of the requirement of accumulated values for calculating the first month's SPEI, the observed SPEI is calculated for the $1951-2016$ period.

To classify the homogeneous drought regions in East Asia sharing a similar hydroclimate, hierarchical clustering analysis using Ward's method was applied to the time series of annual minimum SPEI for each grid point in East Asia. The Ward's method uses classical sum-of-square criterion to minimize within-cluster dispersions. We defined the optimum number of clusters when the inter-cluster distance for a certain cluster decreased sharply (supplementary, Fig. S1).

The bias correction analysis presented in Ho et al. (2012) and Hawkins et al. (2013) was applied to the CESM model data to correct model biases. Below equation is detailed calculation procedure. 


$$
G C M_{B C}(t)=\overline{O B S_{c \lim }}+\frac{\sigma_{O B S, \text { clim }}}{\sigma_{G C M, \text { hist }}}\left[G C M_{R A W}(t)-\overline{G C M_{\text {hist }}}\right]
$$

In Eq. (3), $G C M_{B C}(t)$ and $G C M_{R A W}(t)$ are bias corrected and raw values of the model data at certain time $t$, respectively. $\overline{O B S_{\text {clim }}}$ and $\overline{G C M_{\text {hist }}}$ are the mean values of the observation and model during reference periods of climatology and historical run, respectively (here, reference periods of climatology and historical run are the same as 1950 - 2005). $\sigma_{O B S, \text { clim }}$ and $\sigma_{G C M, \text { hist }}$ are the standard deviations of the observation and model, respectively. According to the equation, it can correct biases not only in the mean value but also of in the temporal variability of the climate model dataset (Ho et al. 2012).

\section{TWO NIER SCENARIOS OVER EAST ASIA}

Much attention has been to reducing the emissions of greenhouse gases and air pollutants to mitigate the impact of future climate change. To consider the effects of the strategies for climate change mitigation in East Asian countries, we designed two RCP-based scenarios, high and low greenhouse gas emissions pathways scenarios of the National Institute of Environmental Research in South Korea (NIER; hereafter NIER-H and NIER-L, respectively) that reflect the environmental policies of the South Korea, China, and Japan (Fig. 1). NIER-H considers rapid development and population increases that assume no further efforts for reducing greenhouse gas emissions will be made in the three countries, while the NIER-L scenario that assumes maximum achievements of the reduction goals of greenhouse gases and air pollutants with the national strategies of South Korea, China, and Japan. The two NIER scenarios are based on RCP8.5 scenarios across the globe, but future emission inventories for East Asia are modified up to 2100 with a consideration of the environmental policies, socioeconomic, and demographic characteristics of the three countries.

To construct the NIER-H and NIER-L, we set 2010 as the reference year and combined three different emission inventories, Evaluating the Climate and Air Quality Impacts of Short-Lived Pollutants (ECLIPSE) of the Greenhouse Gas and Air Pollution Interactions and Synergies-Global (GAINS-Global) for the globe, NIER and Konkuk University Comprehensive Regional Emissions inventory for Atmospheric Transport Experiment (NIER/KU-CREATE) for Asia (Woo et al. 2012; Woo 2013), and Clean Air Policy Supporting System (CAPSS) for South Korea, as the reference inventory for future emission projections. After constructing the reference inventory, we estimated future projection factors until 2100 for the three countries using the Asia-Pacific Integrated Model (AIM; Kainuma et al. 2003) for South Korea and Japan and the Model for Energy Supply Strategy Alternatives and their General Environmental Impact (MESSAGE; IIASA 2009) for China based on future energy growth and policy control scenarios. Differing from RCPs that were developed fundamentally based on the past socioeconomic model of special report on emission scenarios (SRES) (Ward et al. 2012), the AIM and MESSAGE in this study use the latest trends of numerous socioeconomic factors such as, population, gross domestic product (GDP), policy control, and costs of industrial energy, as input data and estimate the future pathway of the total energy demand in each country. For other countries across the globe, we estimated the future projection factors based on the RCP8.5 scenario. Before 2010, we assessed a past projection factor based on ECLIPSE version 5, covering the entire globe, by

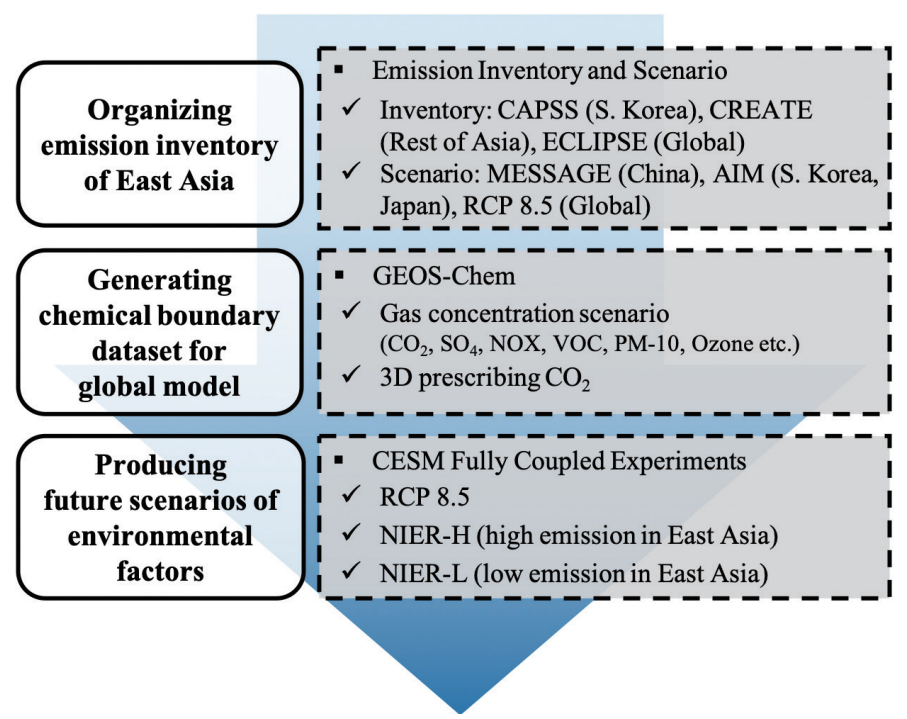

Fig. 1. Flow chart of East Asian emission scenario production. 
country, sector, and fuel type. The emission inventory of the two local emission scenarios was generated from 1995 to 2100 by applying the future and past projection factors on the reference inventory from 2010.

We used a linked system of GEOS-Chem and CESM (Kim et al. 2015) to produce future climate simulations based on the three emissions scenarios, i.e., RCP8.5, NIER-H, and NIER-L, from 2006 to 2100. Historical simulation from 1950 to 2005 was also performed to evaluate the model's skill against observations. Details of the system configurations are provided in Kim et al. (2015). We performed the three scenario simulations (the RCP8.5 and two NIER scenarios) using the BRCP85CN component set, which is for fully coupled experiments with the carbonnitrogen cycle assuming well-mixed atmospheric $\mathrm{CO}_{2}$. For the NIER-H and NIER-L experiments, we modified the radiation modules in the Community Atmospheric Model 4 (CAM4) in CESM to consider the radiative effects of the three-dimensional distributions of $\mathrm{CO}_{2}$ like other gases and aerosols to prescribe the generated East Asian emission inventories. Based on these frameworks, we produced three different climate simulations that reflect different strategies on climate change mitigation in East Asia.

Figure 2 displays the time series of $\mathrm{CO}_{2}$ concentration during the future period for each scenario. From the effects of emission reduction policies of the three major emitters in East Asia, the two NIER scenarios show lower concentrations than RCP8.5, in particular NIER-L. The two NIER scenarios also indicate clearly smaller increasing trends of other greenhouse gases, such as $\mathrm{CH}_{4}$, compared to RCP8.5 (not shown). The gap between the three scenarios becomes larger from the 2030s due to their exponential increasing trend. It is noteworthy that the $\mathrm{CO}_{2}$ concentration in 2100 of NIER scenarios is similar to that of RCP6.0 (IPCC 2014). This implies even reduction of greenhouse gas emissions in the three East Asian countries could substantially alter the climate change pathway.

\section{DROUGHT PROJECTIONS}

\subsection{Changes in Drought During the Observed Period}

East Asia consists of various hydroclimate regimes from desert in the northwest region to tropical rainforest in the south region. Accordingly, drought characteristics may vary according to regions of similar hydroclimate. To identify changes in the drought intensity for specific hydrological regions in East Asia, we applied a clustering analysis to the annual minimum SPEI time series during 1951 - 2016 for all individual grid points. The analysis identifies four distinct drought regions in East Asia (Fig. 3): northwest (R1), northeast and northern middle (R2), southern middle (R3), and south (R4) parts of East Asia. The meridional placement of the four drought regions seems to represent distinct hydroclimates in East Asia, i.e., regions with a dry and cold climate in the high latitudes and a humid and warm climate in the low latitudes. In comparison, Oh et al. (2014) suggested six drought regions based solely on precipitation variations. This result indicates that drought regions in East Asian can be further simplified into these four regions by considering the balance between water supplies (precipitation) and demands (PET).

Figure 4 presents the interannual variation of mean drought intensity (annual minimum value of SPEI) in the four drought regions. It is noted that the increasing trend of drought intensification is stronger for higher latitude regions. The linear regression slope shows that the drought intensity in R1 has increased by -0.2 decade $^{-1}$ during the 60 years of the observational period as relatively mild droughts in the 1950s became more severe droughts in the 2010s. On the contrary, R4 shows no trend and only mild droughts occurred in the 2010s. To identify related physical variation to this asymmetric pattern between northern and southern East Asia in the recent periods, we analyzed the interannual variation of precipitation and PET for each drought region (Fig. 5). It is found that PET is a dominant factor to drive the meridional drought intensification trend of Fig. 4; while there is no significant precipitation trend, PET shows clear increasing trend which is stronger in higher latitude regions. When we checked the variation of the environmental variables used in calculation of CRU PET, this may be caused by much more rapid warming in the higher latitudes than in the lower latitudes (supplementary, Fig. S2). Previous studies presented similar warming trend in conjunction with an increase in precipitation in southern East Asia (e.g., Zhao et al. 2010; Dai 2011; Guan et al. 2015; Zhang and Zhou 2015; Li et al. 2016).

\subsection{Future Drought Projections}

Before running the future projections, we examined the biases of the CESM simulation for key hydrological components, including precipitation and PET against the CRU observation-inferred analysis data (Fig. 6). The simulated PET was estimated using the Penman-Monteith method, similar to the observation's PET. The general spatial patterns of the mean precipitation, PET, and their differences during the period 1950 - 2005 are somewhat similar between the observation and the model. In the case of the precipitation minus PET, the model shows an opposite signal between southeastern China and the northern Indochina Peninsula. The model biases for the absolute values of precipitation and precipitation minus PET are positive (negative) in northern (southern) East Asia. The model tends to overestimate PET in most of East Asia except for some northern areas. Based on the model evaluation, we applied a bias correction analysis of Ho et al. (2012) and Hawkins et al. (2013) to the model results for both the historical and three future scenarios runs. As a result, mean biases of model in Fig. 6 
were considerably reduced (supplementary, Fig. S3). Similar to the mean biases, the biases of temporal variability of model's precipitation, PET, and their difference were also well corrected (not shown).

Figure 7 shows the interannual variation of the mean drought intensity during the present-day (1951 - 2005) and the future (2006 - 2100) periods for each drought region. Despite some discrepancies in the interannual variations between the model and the observation, the simulated decadal-scale variations (11-years running mean) are similar to observations in the present-day period. In addition, the changing trends in the drought intensity under the all three emissions scenarios are consistent with the observed trend after the 1990s. Thus, the model appears to be capable of replicating the long-term trend in the drought intensity in East Asia.

Similar to the observations, results under all future scenarios show a meridional intensification trend of drought in East Asia during the future period. The steepest slope of increase in drought intensity is detected in R1, while in R4, the drought intensity would be decreased. The similar spatiotemporal variation of drought under both of the RCP8.5 and the two NIER scenarios suggests that the effects of regional greenhouse gas emission control in East Asia may be too minor to derive dramatic changes in long-term trend direction of drought intensity, which seems to be induced by environmental forcing of global warming.

To quantitatively identify the future trend of drought intensification for each region, we calculated the linear regression slopes for 2006 - 2100, as shown in Fig. 7 (Table 1). The drought intensification trend in R1 and R2 under the NIER-L and NIER-H scenarios is smaller than under the RCP8.5; NIER-L shows the lowest intensification trend. The trend in R3 indicates no distinct differences between the three scenarios compared to R1 and R2. In $\mathrm{R} 4$, nearly no trend is detected under NIER-L and NIER-H compared to the opposite drought intensification trend (i.e., flood trend) observed under RCP8.5. In summary, the effects of greenhouse gas emissions reduction in South Korea, China, and Japan would contribute to not only alleviation of the drought intensity in those regions but also the prevention of the extreme water imbalances of northern drought and southern flood in East Asia during the future period.

\section{CONCLUSION}

In this study, we projected the future changes in drought intensity in East Asia under three climate change scenarios, RCP8.5 and two NIER scenarios considering the recent environmental policies of East Asian countries. For the NIER scenarios, we employed the GEOS-Chem model in conjunction with the latest greenhouse gas emission reduction plans of South Korea, China, and Japan, to generate the greenhouse gas emission boundary datasets for CESM simulation. These boundary datasets directly applied to the fully coupled simulation of CESM, and then, the two future limiting greenhouse gas emission scenarios, NIER-L and NIER-H as the low and high emission assumption scenarios, respectively, were generated.

Before analyzing future projections, we examined the historical droughts using the SPEI, which considers both water supply and demand. We identified four distinct drought regions in East Asia and found that droughts are more rapidly intensified in high-latitude regions than in low-latitude regions. Similar to the present-day period, the future droughts projected under the above three emissions scenarios suggest that the relatively strong drought intensification in high-latitude regions would continue in the future period. Moreover, under all future scenarios, further drought intensification is expected to occur until 2100 , the end of the projection period. It is noteworthy that even though we prescribed reduced greenhouse gas emissions over East Asia for NIER-H and NIER-L compared to the RCP8.5, there were no robust changes in the long-term trend direction for the future drought intensity. This implies that the greenhouse gas emission control in East Asia alone may be insufficient for altering the drought intensification trend induced by global warming. Accordingly, worldwide cooperation on the greenhouse gas emission reduction may be important for the prevention of the extreme drought disaster in East Asia.

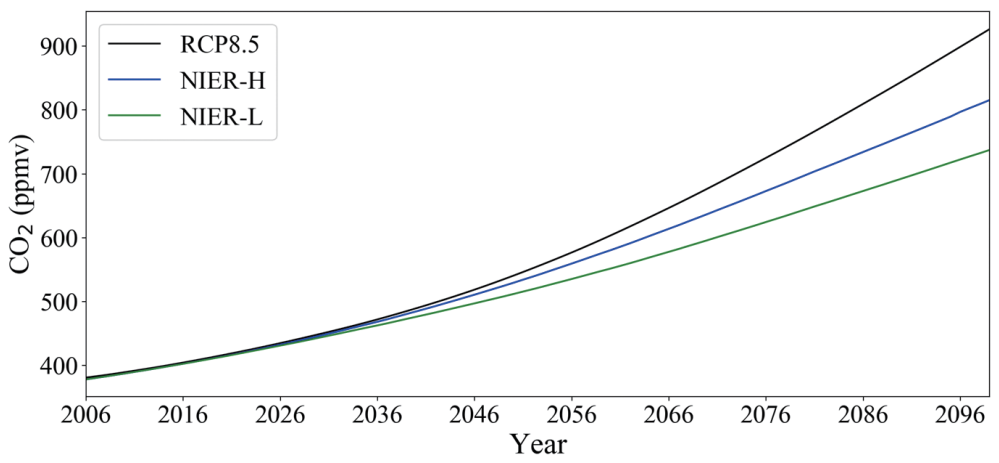

Fig. 2. Interannual variations of $\mathrm{CO}_{2}$ concentration (unit: ppmv) over the globe for each scenario. 


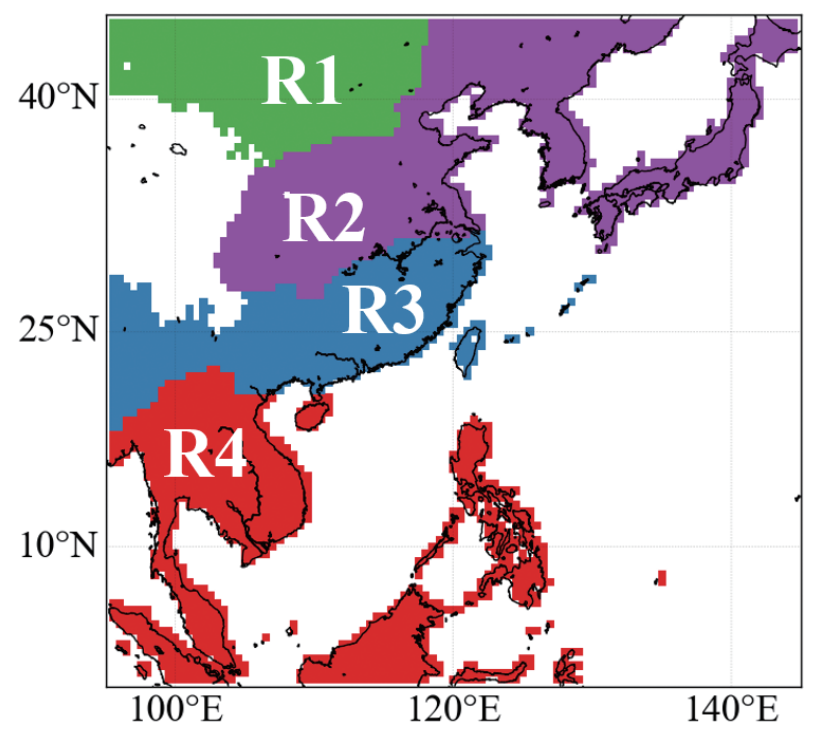

Fig. 3. Distribution of the four drought regions in East Asia.

(a) R1

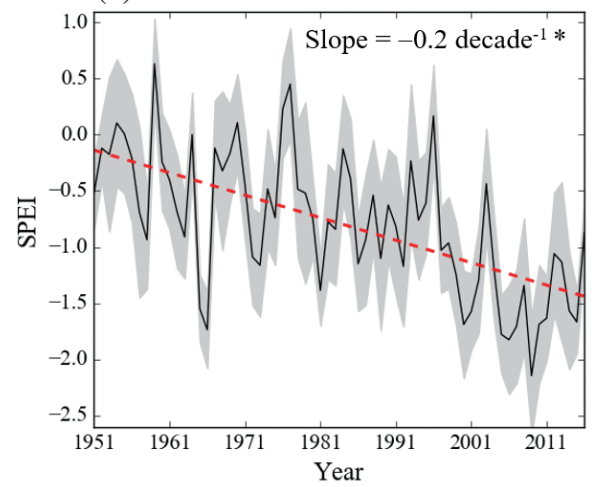

(c) R3

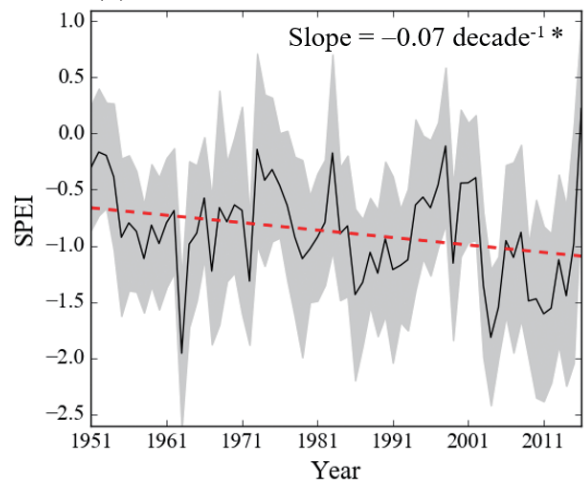

(b) R2

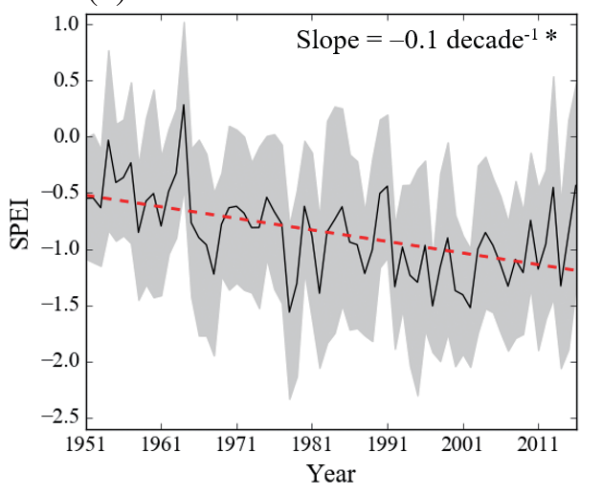

(d) R4

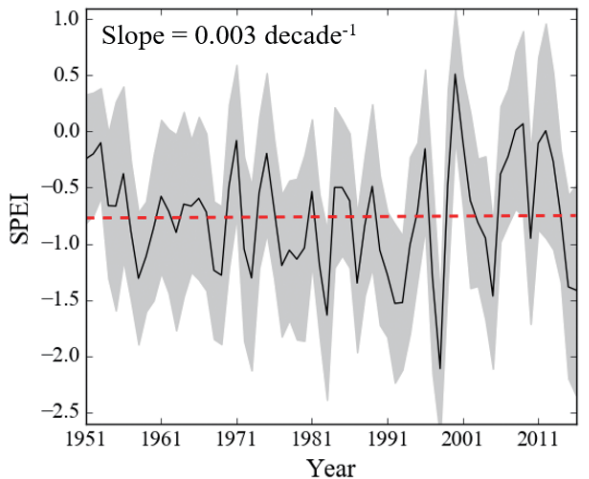

Fig. 4. Annual mean drought intensity for each drought region. Gray area and red dashed line represent one standard deviation and linear regression line, respectively. *: indicate statistical significance at a $95 \%$ confidence level. 


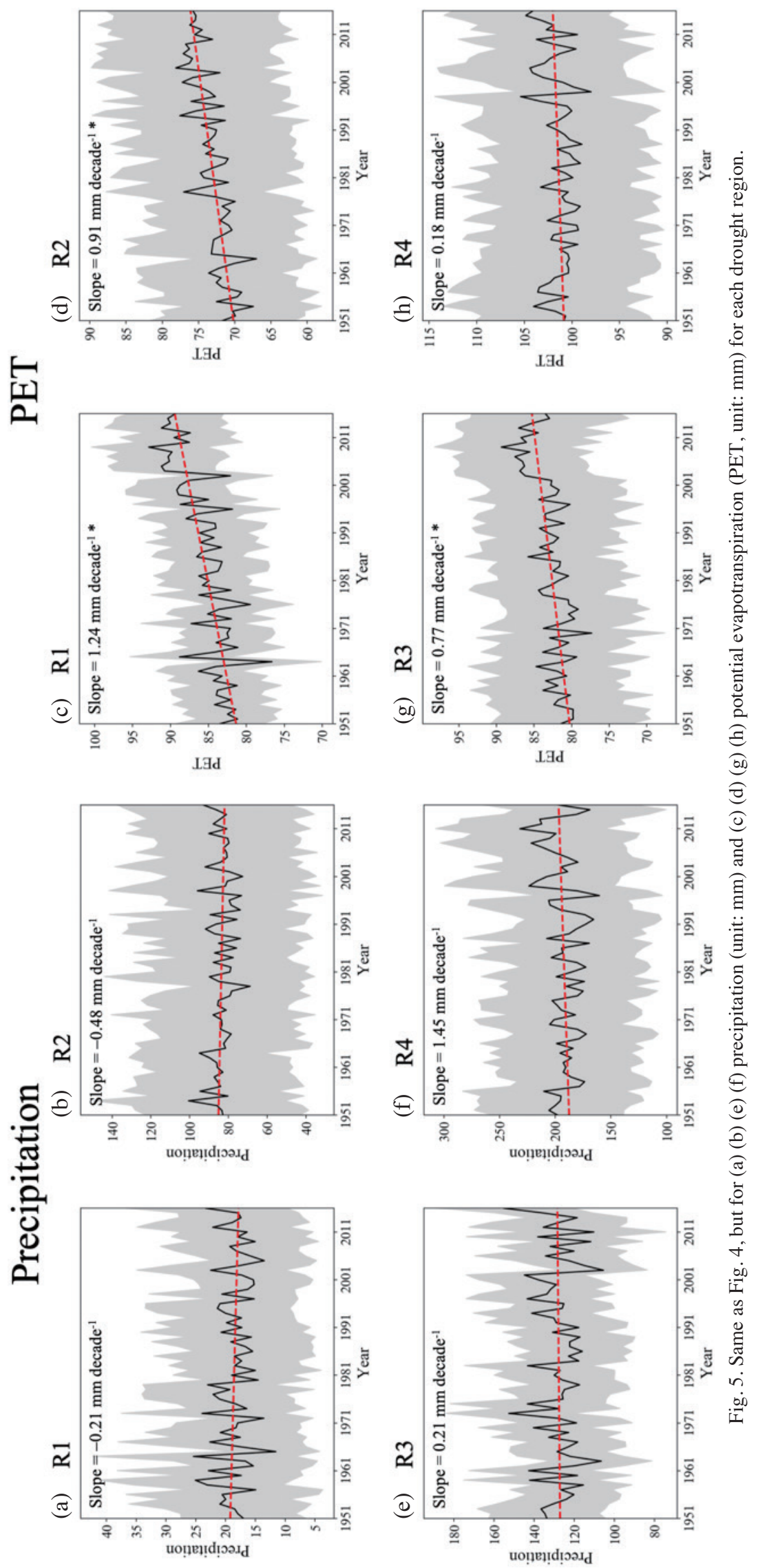


P

(a)

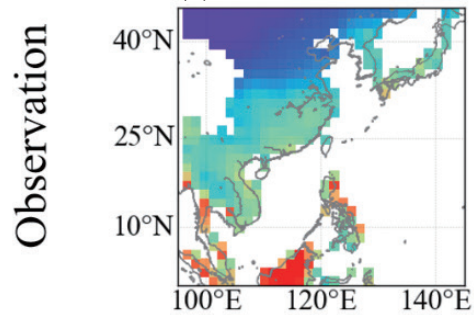

(d)

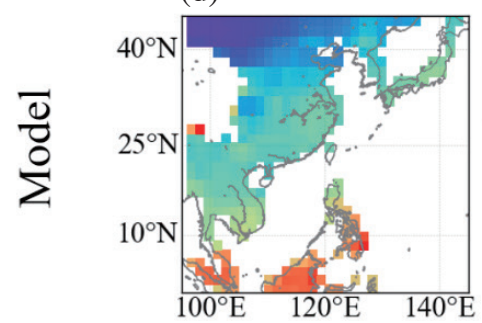

(g)

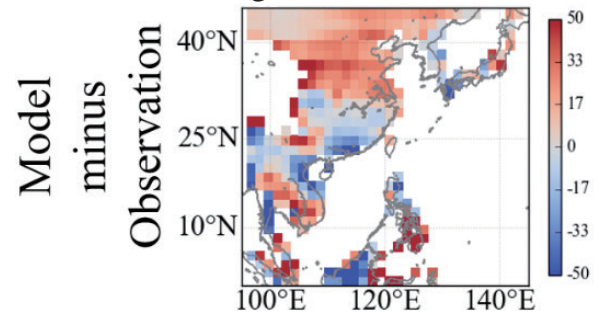

PET

(b)

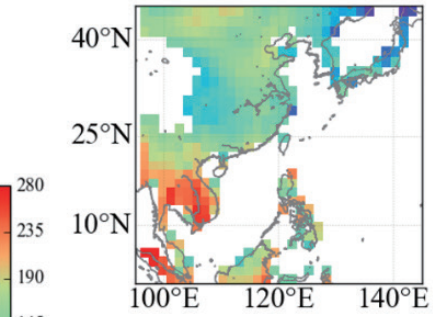

(e)

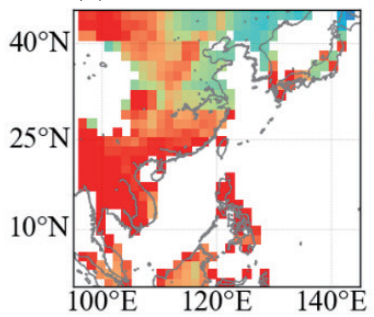

(h)

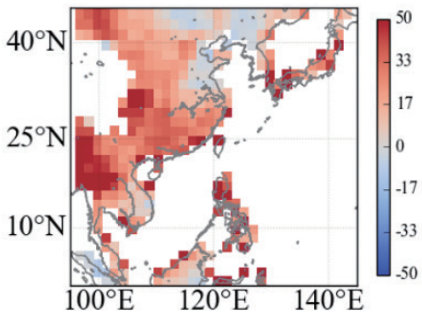

$\mathrm{P}$ minus PET

(c)

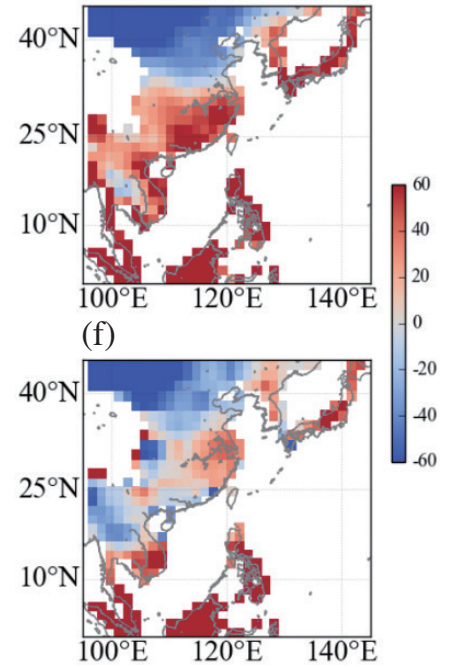

(i)

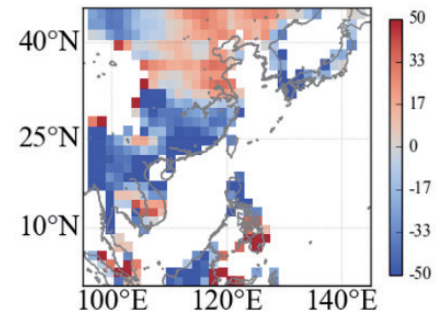

Fig. 6. Map of (a) (d) mean precipitation (P, unit: mm), (b) (e) mean potential evapotranspiration (PET, unit: mm), and (c) (f) their differences for observation and model during 1950 - 2005. (g) (h) (i) show the model biases compared to observation.

(a) R1

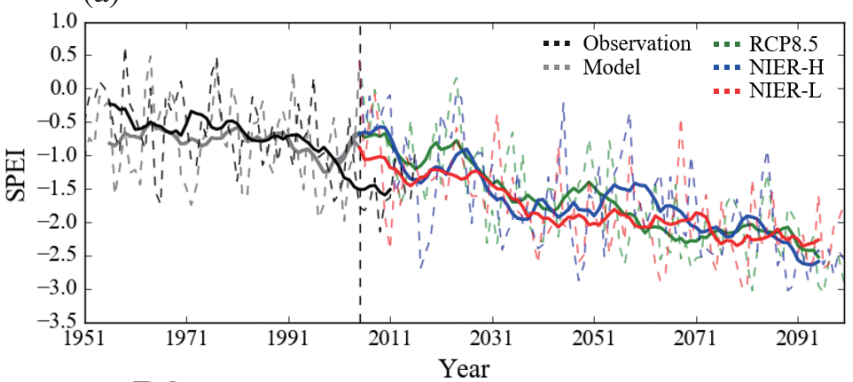

(c) R3

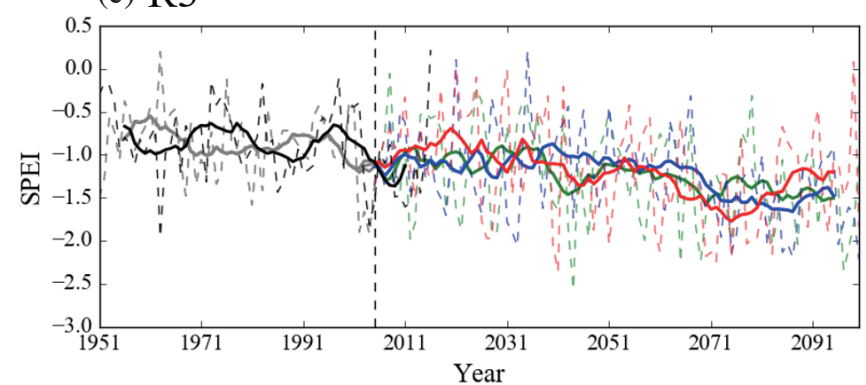

(b) R2

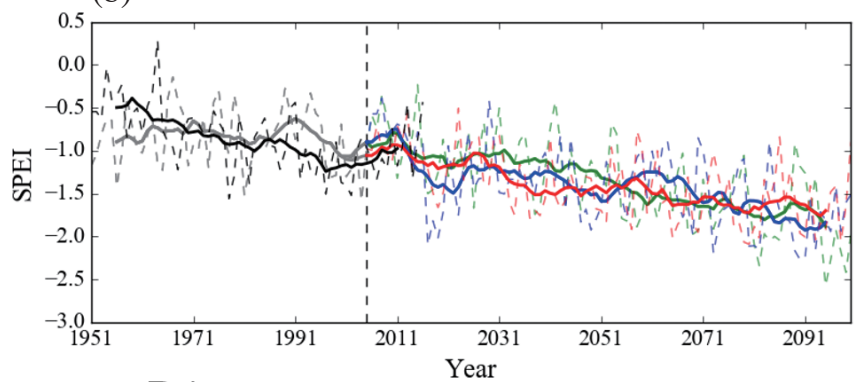

(d) R4

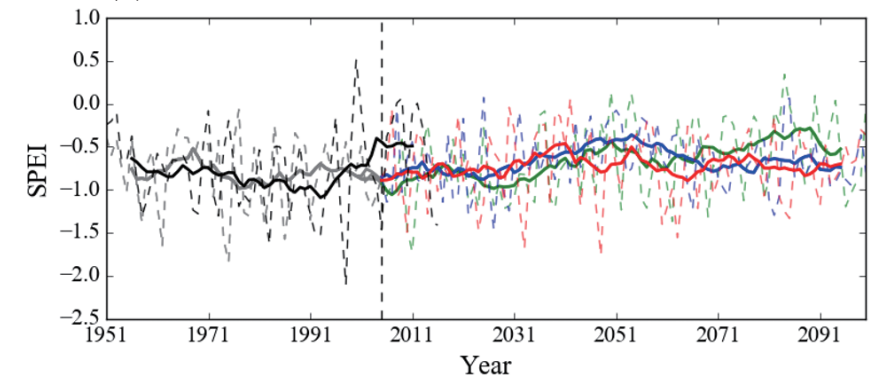

Fig. 7. Same as Fig. 4, but for the present to future periods $(1951-2100)$ for observation and each scenario. The vertical dashed line indicates the boundary between present and future periods. The solid lines depict the 11-years running mean. 
Table 1. Linear regression slopes (century ${ }^{-1}$ ) of the time series in Fig. 7.

\begin{tabular}{c|c|ccc}
\hline \multirow{2}{*}{$\begin{array}{c}\text { Drought } \\
\text { Region }\end{array}$} & $\begin{array}{c}\text { Present Period (Model): } \\
\text { 1951 - 2005 }\end{array}$ & \multicolumn{3}{|c}{ Future Period: 2006 - 2100 } \\
\cline { 3 - 5 } & -0.57 & RCP 8.5 & NIER-H & NIER-L \\
\hline R1 & -0.27 & $-1.96^{*}$ & $-1.71^{*}$ & $-1.33^{*}$ \\
R2 & -0.61 & $-0.66^{*}$ & $-0.9^{*}$ & $-0.76^{*}$ \\
R3 & -0.31 & $0.56^{*}$ & 0.074 & $-0.66^{*}$ \\
R4 & &
\end{tabular}

Note: * Significance at the $95 \%$ confidence level.

Although drought continuously becomes more severe in the high-latitude regions, including in most of China, South Korea, and Japan, under all future scenarios, its intensification rate can be slowed substantially for different emissions levels. Thus, it could say that the local emissions reduction efforts in the three countries have regional merits. If they well follow and reinforce their present environmental policies, the destructive damages caused by potential future droughts would be reduced significantly. It was also found that the water imbalance trend in East Asia, the strengthening of droughts (floods) in high (low) latitude regions, would be reduced under the two NIER scenarios as compared to the RCP8.5. In connection with the long-term trend of floods in low latitude regions of East Asia, previous studies suggested that the precipitation in this region will significantly increase in the future period (Lau et al. 2013; Kent et al. 2015). This may be caused by both of the "richget-richer" mechanism of water vapor and the changes in tropical dynamics such as strengthening of convection from the global warming (Liu et al. 2018). Because it is known that the increases in carbon dioxide could directly strengthen the factors above (Bony et al. 2013), this weakening tendency of floods under NIER scenarios compared to under RCP8.5 may be another robust reference to the necessity of greenhouse gas emissions reduction. To sum up, the results of this study suggest that the implementation of strict environmental policies in East Asian countries would be important and effective for alleviating hydrological disasters in East Asia in the future climate.

Acknowledgements This work was supported by a grant from the National Institute of Environment Research (NIER2018-01-02-028), funded by the Ministry of Environment (MOE) of the Republic Korea. The scenario RCP8.5 of CESM was partially supported by the Korea Environmental Industry \& Technology Institute (KEITI) as part of the Climate Change Correspondence Program of MOE. Figures $\mathrm{S} 1, \mathrm{~S} 2$, and $\mathrm{S} 3$ are in the supplement material.

\section{REFERENCES}

Allen, R. G., M. Smith, L. S. Pereira, and A. Perrier, 1994:
An update for the calculation of reference evapotranspiration. ICID Bull., 43, 35-92.

Bony, S., G. Bellon, D. Klocke, S. Sherwood, S. Fermepin, and S. Denvil, 2013: Robust direct effect of carbon dioxide on tropical circulation and regional precipitation. Nat. Geosci., 6, 447-451, doi: 10.1038/ngeo1799. [Link]

Byun, H.-R., S.-J. Lee, S. Morid, K.-S. Choi, S.-M. Lee, and D.-W. Kim, 2008: Study on the periodicities of droughts in Korea. Asia-Pacific Journal of Atmospheric Sciences, 44, 417-441.

Central Committee of the Communist Party of China (CCCPC), 2016: The 13th Five-Year Plan, Central Committee of the Communist Party of China, China, $219 \mathrm{pp}$.

Chen, D., G. Gao, C.-Y. Xu, J. Guo, and G. Ren, 2005: Comparison of the Thornthwaite method and pan data with the standard Penman-Monteith estimates of reference evapotranspiration in China. Clim. Res., 28, 123 132, doi: 10.3354/cr028123. [Link]

Chen, H.-P., J.-Q. Sun, and X.-L. Chen, 2013: Future changes of drought and flood events in China under a global warming scenario. Atmos. Ocean. Sci. Lett., 6, 8-13, doi: 10.1080/16742834.2013.11447051. [Link]

Cook, B. I., J. E. Smerdon, R. Seager, and S. Coats, 2014: Global warming and $21^{\text {st }}$ century drying. Climate Dyn., 43, 2607-2627, doi: 10.1007/s00382-014-2075-y. [Link]

Cook, B. I., T. R. Ault, and J. E. Smerdon, 2015: Unprecedented $21^{\text {st }}$ century drought risk in the American Southwest and Central Plains. Science Advances, 1, e1400082, doi: 10.1126/sciadv.1400082. [Link]

Council for Science of Japan (CSJ), 2016: National Energy and Environment Strategy for Technological Innovation Towards, Council for Science of Japan, Japan, 39 pp.

Dai, A., 2011: Drought under global warming: A review. WIREs Clim. Change, 2, 45-65, doi: 10.1002/wcc.81. [Link]

Duan, W., B. He, K. Takara, P. Luo, M. Hu, N. E. Alias, and D. Nover, 2015: Changes of precipitation amounts and extremes over Japan between 1901 and 2012 and their connection to climate indices. Climate Dyn., 45, 
2273-2292, doi: 10.1007/s00382-015-2778-8. [Link]

Guan, X., J. Huang, R. Guo, H. Yu, P. Lin, and Y. Zhang, 2015: Role of radiatively forced temperature changes in enhanced semi-arid warming in the cold season over East Asia. Atmos. Chem. Phys., 15, 13777-13786, doi: 10.5194/acp-15-13777-2015. [Link]

Harris, I., P. D. Jones, T. J. Osborn, and D. H. Lister, 2014: Updated high-resolution grids of monthly climatic observations - the CRU TS3.10 dataset. Int. J. Climatol., 34, 623-642, doi: 10.1002/joc.3711. [Link]

Hawkins, E., T. M. Osborne, C. K. Ho, and A. J. Challinor, 2013: Calibration and bias correction of climate projections for crop modelling: An idealised case study over Europe. Agric. For. Meteorol., 170, 19-31, doi: 10.1016/j.agrformet.2012.04.007. [Link]

Ho, C. K., D. B. Stephenson, M. Collins, C. A. T. Ferro, and S. J. Brown, 2012: Calibration strategies: A source of additional uncertainty in climate change projections. Bull. Amer. Meteorol. Soc., 93, 21-26, doi: 10.1175/2011BAMS3110.1. [Link]

International Institute for Applied Systems Analysis (IIASA), 2009: Energy modeling framework: Model for energy supply strategy alternatives and their general environmental impact (MESSAGE), International Institute for Applied Systems Analysis 26th April 2009. Available at http://www.iiasa.ac.at/Research/ENE/ model/message.html.

IPCC, 2014: Climate Change 2014: Synthesis Report. Contribution of Working Groups I, II and III to the Fifth Assessment Report of the Intergovernmental Panel on Climate Change, IPCC, Geneva, Switzerland, 151 pp. Available at https://www.ipcc.ch/report/ar5/syr/.

Kainuma, M., Y. Matsuoka, and T. Morita, 2003: Climate Policy Assessment: Asia-Pacific Integrated Modeling, Springer, Tokyo, 402 pp, doi: 10.1007/978-4-43153985-8. [Link]

Karl, T. R., B. E. Gleason, M. J. Menne, J. R. McMahon, R. R. Heim, M. J. Brewer, K. E. Kunkel, D. S. Arndt, J. L. Privette, J. J. Bates, P. Y. Groisman, and D. R. Easterling, 2012: U.S. temperature and drought: Recent anomalies and trends. Eos, Trans. AGU, 93, 473-474, doi: 10.1029/2012EO470001. [Link]

Kent, C., R. Chadwick, and D. P. Rowell, 2015: Understanding uncertainties in future projections of seasonal tropical precipitation. J. Climate, 28, 4390-4413, doi: 10.1175/JCLI-D-14-00613.1. [Link]

Kim, C. J., M. J. Park, and J. H. Lee, 2014: Analysis of climate change impacts on the spatial and frequency patterns of drought using a potential drought hazard mapping approach. Int. J. Climatol., 34, 61-80, doi: 10.1002/joc.3666. [Link]

Kim, D.-W. and H.-R. Byun, 2009: Future pattern of Asian drought under global warming scenario. Theor. Appl. Climatol., 98, 137-150, doi: 10.1007/s00704-008- 0100-y. [Link]

Kim, D.-W., H.-R. Byun, K.-S. Choi, and S.-B. Oh, 2011: A spatiotemporal analysis of historical droughts in Korea. J. Appl. Meteorol. Climatol., 50, 1895-1912, doi: 10.1175/2011JAMC2664.1. [Link]

Kim, M. J., R. J. Park, C.-H. Ho, J.-H. Woo, K.-C. Choi, C.K. Song, and J.-B. Lee, 2015: Future ozone and oxidants change under the RCP scenarios. Atmos. Environ., 101, 103-115, doi: 10.1016/j.atmosenv.2014.11.016. [Link]

Lau, W. K.-M., H.-T. Wu, and K.-M. Kim, 2013: A canonical response of precipitation characteristics to global warming from CMIP5 models. Geophys. Res. Lett., 40, 3163-3169, doi: 10.1002/grl.50420. [Link]

Li, Z., S. Yang, B. He, and C. Hu, 2016: Intensified springtime deep convection over the South China Sea and the Philippine Sea dries Southern China. Sci. Rep., 6, doi: 10.1038/srep30470. [Link]

Liu, H.-W., J.-Y. Yu, and C.-A. Chen, 2018: Changes of tropical precipitation and convective structure under global warming projected by CMIP5 model simulations. Terr. Atmos. Ocean. Sci., 29, 429-440, doi: 10.3319/TAO.2017.11.29.01. [Link]

McEvoy, D. J., J. L. Huntington, M. T. Hobbins, A. Wood, C. Morton, M. Anderson, and C. Hain, 2016: The evaporative demand drought index. Part II: CONUSWide assessment against common drought indicators. J. Hydrometeorol., 17, 1763-1779, doi: 10.1175/JHMD-15-0122.1. [Link]

Min, S.-K., W.-T. Kwon, E.-H. Park, and Y. Choi, 2003: Spatial and temporal comparisons of droughts over Korea with East Asia. Int. J. Climatol., 23, 223-233, doi: 10.1002/joc.872. [Link]

Ministry of Environment of Korea (MEK), 2015: The Second Climate Change Adaptation, Ministry of Environment of Korea, Korean, 243 pp. (in Korean)

Moss, R. H., J. A. Edmonds, K. A. Hibbard, M. R. Manning, S. K. Rose, D. P. van Vuuren, T. R. Carter, S. Emori, M. Kainuma, T. Kram, G. A. Meehl, J. F. B. Mitchell, N. Nakicenovic, K. Riahi, S. J. Smith, R. J. Stouffer, A. M. Thomson, J. P. Weyant, and T. J. Wilbanks, 2010: The next generation of scenarios for climate change research and assessment. Nature, 463, 747-756, doi: 10.1038/nature08823. [Link]

National Archives of Korea (NAK), 2007: A White Paper of Natural Disaster, National Archives of Korea, Korean, 729 pp. (in Korean)

Naumann, G., L. Alfieri, K. Wyser, L. Mentaschi, R. A. Betts, H. Carrao, J. Spinoni, J. Vogt, and L. Feyen, 2018: Global changes in drought conditions under different levels of warming. Geophys. Res. Lett., 45, 3285-3296, doi: 10.1002/2017GL076521. [Link]

Oh, S.-B., H.-R. Byun, and D.-W. Kim, 2014: Spatiotemporal characteristics of regional drought occurrence in East Asia. Theor. Appl. Climatol., 117, 89-101, doi: 
10.1007/s00704-013-0980-3. [Link]

Park, C.-E., S.-J. Jeong, M. Joshi, T. J. Osborn, C.-H. Ho, S. Piao, D. Chen, J. Liu, H. Yang, H. Park, B.-M. Kim, and S. Feng, 2018: Keeping global warming within 1.5 ${ }^{\circ} \mathrm{C}$ constrains emergence of aridification. Nat. Clim. Change, 8, 70-74, doi: 10.1038/s41558-017-0034-4. [Link]

Park, C.-K. and S. D. Schubert, 1997: On the nature of the 1994 East Asian summer drought. J. Climate, 10, 10561070, doi: 10.1175/1520-0442(1997)010<1056:OTN OTE $>2.0 . C O ; 2$. [Link]

Park, C.-K., H.-R. Byun, R. Deo, and B.-R. Lee, 2015: Drought prediction till 2100 under RCP 8.5 climate change scenarios for Korea. J. Hydrol., 526, 221-230, doi: 10.1016/j.jhydrol.2014.10.043. [Link]

Rahman, A. and P. R. Biswas, 1995: Devours resources. Dhaka Courier, 11, 7-8.

Schlaepfer, D. R., J. B. Bradford, W. K. Lauenroth, S. M. Munson, B. Tietjen, S. A. Hall, S. D. Wilson, M. C. Duniway, G. Jia, D. A. Pyke, A. Lkhagva, and K. Jamiyansharav, 2017: Climate change reduces extent of temperate drylands and intensifies drought in deep soils. Nat. Comm., 8, doi: 10.1038/ncomms14196. [Link]

Shen, C., W.-C. Wang, Z. Hao, and W. Gong, 2007: Exceptional drought events over eastern China during the last five centuries. Clim. Change, 85, 453-471, doi: 10.1007/s10584-007-9283-y. [Link]

Tan, C., J. Yang, and M. Li, 2015: Temporal-spatial variation of drought indicated by SPI and SPEI in Ningxia Hui autonomous region, China. Atmosphere, 6, 13991421, doi: 10.3390/atmos6101399. [Link]

Van Vuuren, D. P., J. Edmonds, M. Kainuma, K. Riahi, A. Thomson, K. Hibbard, G. C. Hurtt, T. Kram, V. Krey, J.-F. Lamarque, T. Masui, M. Meinshausen, N. Nakicenovic, S. J. Smith, and S. K. Rose, 2011: The representative concentration pathways: An overview. Clim. Change, 109, 5-31, doi: 10.1007/s10584-011-0148-z. [Link]

Venkataraman, K., S. Tummuri, A. Medina, and J. Perry, 2016: 21st century drought outlook for major climate divisions of Texas based on CMIP5 multimodel ensemble: Implications for water resource management. J. Hydrol., 534, 300-316, doi: 10.1016/j.jhydrol.2016.01.001. [Link]

Vicente-Serrano, S. M., S. Beguería, and J. I. López-More- no, 2010: A multiscalar drought index sensitive to global warming: The standardized precipitation evapotranspiration index. J. Climate, 23, 1696-1718, doi: 10.1175/2009JCLI2909.1. [Link]

Vicente-Serrano, S. M., S. Beguería, J. Lorenzo-Lacruz, J. J. Camarero, J. I. López-Moreno, C. Azorin-Molina, J. Revuelto, E. Morán-Tejeda, and A. Sanchez-Lorenzo, 2012: Performance of drought indices for ecological, agricultural, and hydrological applications. Earth Interact., 16, 1-27, doi: 10.1175/2012EI000434.1. [Link]

Wang, L., X. Yuan, Z. Xie, P. Wu, and Y. Li, 2016: Increasing flash droughts over China during the recent global warming hiatus. Sci. Rep., 6, doi: 10.1038/srep30571. [Link]

Ward, J. D., S. H. Mohr, B. R. Myers, and W. P. Nel, 2012: High estimates of supply constrained emissions scenarios for long-term climate risk assessment. Energ. Pol., 51, 598-604, doi: 10.1016/j.enpol.2012.09.003. [Link]

Woo, J.-H., S.-M. An, D.-Y. Kim, H.-K. Kim, K.-C. Choi, Y. Kim, S.-H. Kwon, J.-G. Yu, K.-S. Kim, and K.-H. Park, 2013: Development of the Asia Emission Inventory in Support of Integrated Modeling of Climate and Air Quality (III), National Institute of Environmental Research, NIER-SP2013-1, Incheon, Korea.

Woo, J.-H., K.-C. Choi, H. K. Kim, B. H. Baek, M. Jang, J.-H. Eum, C. H. Song, Y.-I. Ma, Y. Sunwoo, L.-S. Chang, and S. H. Yoo, 2012: Development of an anthropogenic emissions processing system for Asia using SMOKE. Atmos. Environ., 58, 5-13, doi: 10.1016/j. atmosenv.2011.10.042. [Link]

Yoo, S.-H., C.-H. Ho, S. Yang, H.-J. Choi, and J.-G. Jhun, 2004: Influences of tropical western and extratropical Pacific SST on East and Southeast Asian climate in the summers of 1993-94. J. Climate, 17, 2673-2687, doi: 10.1175/1520-0442(2004)017<2673:IOTWAE >2.0. CO;2. [Link]

Zhang, L. and T. Zhou, 2015: Drought over East Asia: A review. J. Climate, 28, 3375-3399, doi: 10.1175/JCLID-14-00259.1. [Link]

Zhao, P., S. Yang, and R. Yu, 2010: Long-term changes in rainfall over eastern China and large-scale atmospheric circulation associated with recent global warming. $J$. Climate, 23, 1544-1562, doi: 10.1175/2009JCLI2660.1. [Link] 